\title{
A produtividade da Educação Física improdutiva ${ }^{1}$
}

\author{
Giovanni Frizzo*
}

\begin{abstract}
Resumo: Este artigo tem origem nas pesquisas desenvolvidas pelo Grupo de Estudos Qualitativos Formação de Professores e Prática Pedagógica em Educação Física e Ciências do Esporte (F3P-EFICE) da Universidade Federal do Rio Grande do Sul (UFRGS). Para este texto, problematizamos a formação e a prática pedagógica de professores de Educação Física, partindo do conhecimento produzido por este grupo. Buscamos identificar, portanto, as contribuições que estas produções trouxeram para o campo acadêmico acerca da temática da formação de professores e da prática pedagógica em Educação Física e de que forma esta se articula com a realidade educacional brasileira inserida no seio do modo de produção capitalista.
\end{abstract}

Palavras-chave: Educação Física Escolar. Formação de Professores. Prática Pedagógica.

\section{INTRODUÇÃO}

Este trabalho tem origem nas pesquisas desenvolvidas no Grupo de Estudos Qualitativos Formação de Professores e Prática Pedagógica em Educação Física e Ciências do Esporte (F3P-EFICE) da Escola de Educação Física (ESEF) da Universidade Federal do Rio Grande do Sul (UFRGS). O objetivo geral da pesquisa é identificar e compreender as relações e os efeitos gerados na formação profissional e na prática pedagógica dos professores de Educação Física da Rede Municipal de Ensino de Porto Alegre pelas transformações sociais e profissionais a que estão submetidos as escolas e os professores. A partir do trabalho e das experiências vividas por esse coletivo docente, pretende-se oferecer à comunidade científica, aos formadores de professores e aos gestores públicos, conhecimento novo sobre como esses

\footnotetext{
${ }^{1}$ Este título faz referência à obra de Gaudêncio Frigotto. A produtividade da escola improdutiva. São Paulo: Cortez, 1999.

* Mestrando do Programa de Pós-graduação em Ciências do Movimento Humano da Escola de Educação Física da UFRGS, na área Movimento Humano, Cultura e Educação. Porto Alegre, RS. Brasil. E-mail: gfrizzo2@ig.com.br
} 
atores organizam seu mundo profissional e que instrumentos culturais utilizam para dar conta das demandas que a administração pública e as comunidades escolares lhes solicitam.

Através do conhecimento produzido pelo F3P-EFICE, ${ }^{2}$ os objetivos específicos deste estudo são: identificar as contribuições que as produções trouxeram para o campo acadêmico acerca da formação de professores e compreender como se materializa o trabalho pedagógico em Educação Física no modo de produção capitalista. Tem como referência teórica a contribuição de Frigotto (1999) sobre a natureza da relação entre educação e processo produtivo. Este autor afirma que ao apreender a existência desse vínculo, percebe que não se trata de um vínculo imediato e direto, mas mediato e indireto.

A concepção de trabalho pedagógico que utilizamos neste estudo faz referência a uma noção ampliada do trabalho produzido pelo professor na escola e de suas possibilidades de articulação entre a macroestrutura sócio-política e o cotidiano da docência nos espaços escolares. Nesse sentido, entendemos que a concepção de trabalho docente, prática pedagógica, ou prática docente não são suficientes para dar conta do universo de compreensão que o trabalho pedagógico possibilita na concreticidade do seu desenvolvimento e na materialidade da sua práxis. A escola, por exemplo, ao fragmentar seu trabalho, parece não só forjar a separação destes conceitos, mas também produzir uma distância surreal entre eles, levando à frustração o trabalho de professores e estudantes que desejam e/ou precisam emancipar sua atuação pedagógica. A reflexão sobre essas questões pode suscitar a revisão de conceitos que são eixos de sustentação do trabalho pedagógico.

Na medida em que se compreende ou mesmo se reduz o significado do trabalho desenvolvido nas escolas a uma prática - prática pedagógica, prática docente-, desloca-se o eixo da problematização do trabalho pedagógico como atividade humana intelectual entendida como práxis humana, na qual se dissocia a relação teoria-prática para um protocolo de atividades burocráticas, que podem ser executadas

\footnotetext{
${ }^{2}$ Foram diversas as publicações sobre esta temática: teses, dissertações, artigos em periódicos nacionais e internacionais, apresentações em Congressos etc

Movimento, Porto Alegre, v. 14, n. 03, p. 209-232, setembro/dezembro de 2008.
} 
por indivíduos que sejam 'treinados' para isso durante a graduação ou no curso de um conjunto de disciplinas acadêmicas denominadas práticas de estágio, estágio docente, práticas de ensino etc., em que o importante é a prática da docência: observar o fazer, aprender como fazer e fazer. As atividades formativas, dentro do percurso formativo do professor têm priorizado, nos currículos, uma certa profissionalização e habilitação profissional que se propõe a desenvolver a capacidade da docência e habilitar para tal (BEZERRA; PAZ, 2006).

Uma tendência importante das atuais pesquisas em educação é a ênfase na descrição e análise do trabalho pedagógico nas escolas. Surgida principalmente a partir da década de 80 , não só apresentou inovações metodológicas importantes, como constitui um conjunto de dados que permitem uma compreensão da dinâmica atual da escola. Nessa caminhada é importante, no entanto, distinguir entre prática e conhecimento, já que a prática determina o conhecimento mas não é, em si mesma, o conhecimento.

Concordando com Freitas (1989), acreditamos ser importante questionar as tendências que defendem que a teoria pedagógica possa ser gerada, na prática da escola, ao invés de surgir a partir da prática. Esta diferenciação significa que a posse da prática não é suficiente para afirmarmos que nela resida uma teoria pedagógica alternativa. Como explicita Kopnin (1978), a teoria, como um momento do pensamento, parte da prática e a ela retorna (como critério de veracidade), mas não antes de empreender o caminho concretosensorial ao concreto, pela via do abstrato.

Esta concepção de trabalho pedagógico parte de uma perspectiva de ciência entendida como um produto social histórico, um fenômeno em contínua evolução, incluída no movimento das formações sociais e determinada pelos interesses e conflitos sociais na qual se produz. O critério de cientificidade se materializa na prática histórica, a explicação e a compreensão do objeto se obtêm na medida em que recuperamos sua gênese e seu desenvolvimento, em que os fenômenos se explicam pela sua própria história. A relação entre sujeito e objeto é definida como concreticidade que se constrói como síntese da relação entre sujeito-objeto.

Movimento, Porto Alegre, v. 14, n. 03, p. 209-232, setembro/dezembro de 2008. 
Nesta perspectiva, o homem é concebido como ser social e histórico que, embora determinado por contextos econômicos, políticos e culturais, é seu criador e agente transformador da realidade. O conhecimento da realidade e a apropriação de elementos que possibilitem uma análise mais avançada do contexto, das dinâmicas sociais e a ação transformadora dos homens se orientam para a obtenção de maiores níveis de liberdade, autonomia e 'desalienação' adquiridos através de permanentes lutas e da superação das contradições sociais. Este mesmo homem, uma totalidade histórica concreta que se distingue dos demais animais e da natureza e se constrói pelas relações sociais de trabalho (produção) que estabelece com os demais homens no modo de produção capitalista, reduz-se e transfigura-se num indivíduo abstrato, cujas características fundamentais são o egoísmo e a racionalidade.

A literatura sobre o trabalho pedagógico na Educação Física não tem oferecido aportes seguros para a análise dos processos mais recentes de mudança, o que justifica a necessidade de investigações que procurem contemplar a difícil articulação entre a macro-realidade dos sistemas educacionais e o cotidiano escolar. Acreditamos que, para problematizar a formação de professores e o trabalho pedagógico, é necessário compreender o modo de produção e o funcionamento da sociedade e analisar criticamente a educação considerando a crise mais geral do modo de produção capitalista. Nesta crise, cada vez mais se define um projeto de mundialização da educação impregnada do viés privatista da empregabilidade. Perseguimos uma tradição do pensamento marxista, concebida na tríade: visão de mundo, método de análise e projeto histórico. Convictos de que esta referência constituise num instrumento mais adequado para enfrentar as problemáticas significativas da atual conjuntura, permitindo articular, dialeticamente, análise e encaminhamentos na forma de proposições político-pedagógicas, além de fornecer análises mais avançadas do modo de produção e reprodução da vida. Destacamos que esta tradição subordina os movimentos da realidade ao conjunto de relações concretas que os homens estabelecem entre si para produção da sua existência material e social. Assim, fundamentada nestes pressupostos, a pesquisa embasada neste referencial teórico-metodológico tem como questão de fundo a crítica à visão estática da realidade assumida por outras linhas de pensamento.

Movimento, Porto Alegre, v. 14, n. 03, p. 209-232, setembro/dezembro de 2008. 
Tal opção exige a aproximação/apropriação dos conceitos e categorias da epistemologia materialista histórica-dialética, especialmente do processo de análise crítica em Marx: a crítica marxista constrói-se por oposição à organização social capitalista; conduz-se sobre o real, em um dado momento concreto; insere-se numa totalidade - totalidade histórica e social; explicita a relação entre os valores burgueses e as condições materiais subjacentes a eles e contribui para a destruição de tais bases; parte da própria análise econômica, situando o processo de produção e reprodução do capital e do valor; e ainda busca a solução para antíteses reais existentes (ENGUITA, 1993). Fizemos a opção por um método que parte da realidade concreta, ou seja, da base material, que permite a análise das partes e do todo. Assim, alicercçamo-nos num pressuposto de que a ciência não existe para atender os anseios de um grupo de intelectuais e pesquisadores, mas sim para, através da constatação e compreensão da realidade, construir propostas transformadoras atendendo às problemáticas significativas, necessárias e vitais da sociedade.

Deste modo, este trabalho, pelo seu teor crítico, preocupa-se em desvendar as contradições apresentadas pelo real, expressas no conflito de interpretações e interesses, para então propor formas de superação, no sentido de transformar essa realidade resgatando sua dimensão histórica. Os fundamentos epistemológicos encontram-se na lógica interna do processo e em decisões metodológicas que desvelam a dinâmica e as contradições dos fenômenos, bem como a relação homem/natureza, reflexão/ação e teoria/prática.

Assim, a ciência é entendida como resultado da produção humana, envolvida na dinâmica da relação entre sujeito e objeto (homem e natureza constituindo-se como categoria histórico-concreta), que segundo GAMBOA (1989, p. 103):

Constrói-se na síntese objeto-sujeito que acontece no ato de conhecer. O concreto é construído como ponto de chegada de um processo que tem origem empírico-objetiva, passa pelo abstrato de características subjetivas, e forma uma síntese, validada na mesma ação de conhecer, quando o conhecido (concreto no pensamento) é confrontado com seu ponto de partida através da prática.

Movimento, Porto Alegre, v. 14, n. 03, p. 209-232, setembro/dezembro de 2008. 
Para apontarmos os questionamentos sobre a realidade do trabalho pedagógico, é necessário discutirmos os fundamentos filosóficos que regem os modelos teóricos do trabalho. Pode-se dizer que para os economistas clássicos - David Ricardo, Adam Smith - a relação do trabalhador com o objeto de trabalho era uma relação de transformação do objeto pelo sujeito, sendo que este não se modificava pelo trabalho. Marx, contudo, mostrou que o processo de trabalho transforma dialeticamente não apenas o objeto, mas também o trabalhador, assim como suas condições de trabalho. Trabalho, portanto, não é simplesmente transformar um objeto em alguma outra coisa - outro objeto - é envolver-se numa práxis em que o trabalhador também se transforma por seu trabalho.

[...] o trabalho é um processo de que participam o homem e a natureza, processo em que o ser humano com sua própria ação impulsiona, regula e controla seu intercâmbio material com a natureza como uma de suas forças. [...] atuando assim sobre a natureza externa e modificando-a, ao mesmo tempo modifica sua própria natureza (MARX, 1980, p. 202).

A atuação profissional na educação coloca a necessidade de conhecer os mais variados elementos que envolvem o trabalho pedagógico, a necessidade de compreendê-la da forma mais completa possível. No entanto, não se pode fazer isto sem um caminho que permita, filosófica e cientificamente, compreender a educação. E, se a lógica formal, porque é dual, separando sujeito-objeto, foi se mostrando insuficiente para esta tarefa, parece possível buscar este caminho no método materialista histórico-dialético. Ao contrário da lógica formal, a lógica dialética não pode prescindir de um conteúdo concreto, apesar de ser necessário, para compreendê-la, colocar a dialética de Hegel de ponta-cabeça, por sua característica idealista. O método materialista histórico-dialético é conhecido como o método dialético do abstrato ao concreto,s o ponto de partida é uma clara distinção entre o empírico e o "pensado", no sentido de que o primeiro tem existência independente do segundo. Esta distinção não é tão óbvia já que se pode, inadvertidamente ou intencionalmente, tomar a dialética sem seu fundamento materialista (filosófico). Nesse processo, o movimento dialético tem um objetivo duplo: de um lado

Movimento, Porto Alegre, v. 14, n. 03, p. 209-232, setembro/dezembro de 2008. 
trabalha as determinações abstratas e as relaciona mutuamente entre si, de forma que os opostos definem-se mutuamente; de outro, constitui com eles uma nova totalidade com múltiplas determinações, na qual o que antes aparecia como opostos forma, agora, uma unidade que os compreende e os explica (FREITAS, 1995). Neste sentido, avança do simples (determinações) para o complexo (totalidade), ou, ainda, do abstrato ao concreto pensado. ${ }^{3}$

O princípio da contradição, presente nesta lógica, indica que para pensar a realidade é possível aceitar a contradição, caminhar por ela e apreender o que dela é essencial. Neste caminho lógico, movimentar o pensamento significa refletir sobre a realidade partindo do empírico (a realidade dada, o real aparente, o objeto assim como ele se apresenta à primeira vista) e, por meio de abstrações (elaborações do pensamento, reflexões, teoria), chegar ao concreto: compreensão mais elaborada do que há de essencial no objeto, objeto síntese de múltiplas determinações, concreto pensado. Assim, a diferença entre o empírico (real aparente) e o concreto (real pensado) são as abstrações (reflexões) do pensamento que tornam mais completa a realidade observada. Aqui, percebe-se que a lógica dialética do método não descarta a lógica formal, mas lança mão dela como instrumento de construção e reflexão para a elaboração do pensamento pleno, concreto. Desta forma, a lógica formal é um momento da lógica dialética; o importante é usá-la sem esgotar nela e por ela a interpretação da realidade.

\section{ANÁLISE DE CONJUNTURA}

A reestruturação produtiva, ou o reordenamento do mundo do trabalho, que se solidifica na transformação do modelo fordistal taylorista para a era da acumulação flexível, dotadas de forte caráter destrutivo, têm acarretado um monumental desemprego, precarização

\footnotetext{
${ }^{3}$ É preciso esclarecer, porém, que o ponto de vista a partir do qual a dialética marxista é aqui tratada é a educação e o ponto a partir do qual a educação é tratada aqui, é o pensamento marxista. Portanto, são de e para educadores as análises das idéias marxistas como paradigmas de interpretação da realidade apresentadas neste estudo.

Movimento, Porto Alegre, v. 14, n. 03, p. 209-232, setembro/dezembro de 2008.
} 
do trabalho e uma degradação crescente, na relação metabólica entre homem e natureza, conduzida pela lógica de sociedade voltada prioritariamente para a produção de mercadorias, que destrói o meio ambiente em escala globalizada (ANTUNES, 2000). Este atual momento de mudanças e reestruturações por que passam os setores sociais no Brasil e, em especial, o setor educacional, faz com que, na luta por um novo reordenamento, confrontem-se diferentes projetos históricos. Existe um projeto neoliberal de sociedade e de educação que se consolida de formas específicas, como um projeto hegemônico, no Brasil, América Latina e no mundo, como elemento de um processo de Mundialização do Capital (MELO, 2004), modificando nossas vidas e interferindo no planejamento e realização de nossas políticas. Este projeto é determinado historicamente pelas relações de produção, relações de trabalho e do desenvolvimento das forças produtivas nacional e internacionalmente.

O liberalismo ou neoliberalismo, referencial das forças conservadoras, rearticulou o modelo, recolocando as suas forças e atacando com meios mais suaves do que a violência física praticada pelas ditaduras em quase todos os países latino americanos. Primeiramente foram vítimas do modelo as categorias operárias e os serviços públicos. Os meios usados, eficientemente, foram as privatizações e o emprego de tecnologias avançadas. Ao mesmo tempo em que rebaixavam os salários, desempregavam em massa os operários das fábricas. O capital externo se apropriou do patrimônio público nacional e os governos colocaram-se a serviço do império, tornando os Estados mais violentos e menos prestativos. Com maior ou menor grau de intensidade, as relações de trabalho no mundo inteiro vêm acumulando transformações que beneficiam majoritariamente o capital especulativo e financeiro em detrimento do humano e do trabalhador.

Tendo em vista a postura de asseguramento da política neoliberal para o plano da educação, bem como esta nova investida no que diz respeito à exploração e alienação humana, percebemos, nos dias atuais, a necessidade, por parte do capitalismo, da formação de um novo modelo de trabalhador. A reconfiguração do trabalho, causada pela introdução de novas tecnologias operacionais, altera a base técnica da produção, e traz, ao contrário do trabalhador do modelo tayloristal

Movimento, Porto Alegre, v. 14, n. 03, p. 209-232, setembro/dezembro de 2008. 
fordista $^{4}$ (KUENZER, 1986), executor de tarefas repetitivas e segmentadas, a necessidade da formação para a competitividade: uma formação flexível, abstrata e polivalente.

[...] a relação de luta entre os trabalhadores e o capitalismo flexível tem se mostrado um campo interessante de investigação, dado o amoldamento daqueles primeiros frente à complexificação do mundo do trabalho e da reestruturação produtiva, no que diz respeito à perda das reivindicações históricas de uma sociedade emancipada do trabalho abstrato e produtora de mercadorias. Para um aprofundamento destas questões na educação física é necessário, em um outro momento, perfilar análises da realidade concreta do trabalho realizado pelos professores, mediado pela presente reconfiguração do mundo do trabalho, análises estas que se mostram carentes no campo da nossa literatura (NOZAKI, 2004, p. 05).

Segundo Tardif e Lessard (2005) pode-se dizer que a escola e o ensino têm sido invadidos e continuam ainda a sê-lo, por modelos de gestão e de execução do trabalho oriundos diretamente do contexto industrial e de outras organizações econômicas hegemônicas. A introdução de novas tecnologias na escola (internet, multimídias, computadores, etc.) vai, em geral, no mesmo sentido: o ensino se assemelha a um processo de "tratamento da informação" e se aplicam a ele modelos de racionalização retirados diretamente do trabalho tecnológico, sem questionar sua validade e avaliar seu impacto sobre os conhecimentos escolares, o ensino e a aprendizagem dos estudantes. O mesmo acontece também com as novas abordagens do trabalho (flexibilidade, competências, responsabilidade, eficácia, necessidade de resultados, etc.) que se procura implantar nas escolas, e que provém, na maioria, do contexto industrial e, mais amplamente, das organizações econômicas e empresariais.

\footnotetext{
${ }^{4} \mathrm{O}$ modelo taylorista/fordista caracteriza-se pela produção em massa com controle do tempo e movimento do trabalhador, segmentação das funções desenvolvidas pelo operário, separação entre articuladores intelectuais e executores do trabalho e pela organização vertical nas unidades fabris, ou seja, com a existência da figura do supervisor (Antunes, op.cit., Kuenzer, op.cit.). Aqui percebemos a clássica formulação marxiana de divisão do trabalho, decorrendo da alienação do produto, no caso da sua materialidade, e da alienação do processo, no caso da organização do trabalho.
}

Movimento, Porto Alegre, v. 14, n. 03, p. 209-232, setembro/dezembro de 2008. 
Vivemos, atualmente, a convivência de uma massa inédita de informações disponíveis e uma incapacidade aparentemente insuperável de interpretação dos fenômenos. Vivemos o que alguns chamam de "novo analfabetismo" - porque se é capaz de explicar, mas não de entender -, típico dos discursos econômicos. A diferença entre explicar e entender pode dar conta da diferença entre acumulação de conhecimentos e compreensão do mundo. Explicar é reproduzir o discurso midiático, entender é desalienar-se, é decifrar, antes de tudo, o mistério da mercadoria, é ir para além do capital (SADER, 2005). Os que lutam contra a exploração, a opressão, a dominação e a alienação - isto é, contra o domínio do capital - têm como tarefa educacional a transformação social emancipadora. Como ressalta Mészáros (2005), devemos pensar a sociedade tendo como parâmetro o ser humano, exigindo a superação da lógica desumanizadora do capital, que tem no individualismo, no lucro e na competição os seus fundamentos.

Este mesmo autor defende a existência de práticas educacionais que permitam aos educadores e estudantes trabalharem as mudanças necessárias para a construção de uma sociedade na qual o capital não explore mais o tempo de lazer, pois o que as classes dominantes impõem é uma educação para o trabalho alienado, com o objetivo de manter o homem dominado. Já a educação libertadora teria como função transformar o trabalhador em um agente político, que pensa, age, e usa a palavra como instrumento para transformar a realidade. A educação é sempre uma prática política, na medida em que se insere dentro de um projeto de transformação ou conservação da ordem vigente. Ou seja, alimentar a indignação ética diante das situações de injustiça e indignidade humanas, não perder a sensibilidade frente à lógica da violência, da exclusão, da impunidade que é imposta pelo modelo de sociedade atual, e canalizar esse sentimento de indignação para o despertar da necessidade de mudanças, tanto na sociedade como em cada um de nós.

De acordo com Freitas (1995), a organização do trabalho pedagógico e o trato com o conhecimento na escola e na universidade tende a reproduzir a organização social e a apropriação do conhecimento desenvolvidas na produção da vida material. Considerando que a organização do trabalho pedagógico e o trato com o conhecimento são

Movimento, Porto Alegre, v. 14, n. 03, p. 209-232, setembro/dezembro de 2008. 
dimensões que solidificam o currículo, torna-se importante constatarmos como tais dimensões vêm se concretizando no interior da dinâmica curricular dos cursos de formação de professores, especialmente diante das determinações colocadas pela atual política educacional.

O professor de Educação Física, além do domínio dos conhecimentos gerais e específicos para sua ação profissional, necessita compreender e enfrentar as questões envolvidas com o trabalho pedagógico, seu caráter e organização. Isto implica em compreender e agir sobre o duplo caráter que assume o trabalho: um caráter ontológico de formação do ser humano e outro, de trabalho alienado no modo de produção capitalista. Nesta perspectiva buscar a crítica sobre a base técnica e tecnológica do trabalho do professor de Educação Física e a construção de novas bases científicas para organização do trabalho, a saber, um trabalho na linha do trabalhar emancipatório, solidário, em grupo, com autonomia e auto-organização para tomar decisões, bem como se responsabilizar pelas opções feitas.

\section{FoRMAÇÃO DE PROFESSORES, PRÁTICA PEDAGÓGICA E TRABALHO DOCENTE-PRODUÇÕES DO GRUPO F3P-EFICE}

Iniciamos essa discussão fazendo uma contextualização sobre a formação dos professores de Educação Física na qual, ao analisar o atual currículo de graduação da ESEF da UFRGS, Molina Neto (1997) destaca que a organização do ensino mantém justamente o enfoque acadêmico-enciclopédico combinado com a perspectiva técnica. As mudanças parecem privilegiar aos interesses e modismos do mercado, mais do que a uma preparação mais qualificada para o ensino da Educação Física nas escolas públicas. É interessante sublinhar que, no referido estudo, a formação aparece como um, entre os vários elementos que configuram a cultura docente do professorado de Educação Física (GÜNTHER; MOLINA NETO, 2000). O que tem pautado a formação acadêmica em Educação Física é um saber predominantemente instrumental de caráter funcional, que privilegia a competência técnica do professor, restringindo o trabalho pedagógico à seleção e aplicação de procedimentos instrumentais que possibilitem a máxima eficácia nos resultados. Isso contribui para que o

Movimento, Porto Alegre, v. 14, n. 03, p. 209-232, setembro/dezembro de 2008. 
futuro professor venha a agir sem uma preocupação maior com o caráter pedagógico de sua prática. Uma vez que não lhe foi proporcionado o exercício de análise e reflexão dos conhecimentos adquiridos na graduação, o resultado é a ausência de reflexão que se estende no exercício da profissão.

As demandas de formação de professores respondem a configurações que se originam nas mudanças ocorridas no mundo do trabalho e nas relações sociais, e a configurações oriundas das diferentes posições que são assumidas em relação aos projetos apresentados pelo grupo que ocupa o poder a partir de determinada correlação de forças. Portanto, busca-se explicitar que a idéia de formação humana passa, necessariamente, por interações sociais construídas pelos sujeitos em seu cotidiano, por meio de práticas e instituições relacionadas às formas como as relações sociais e de produção material e não-material se articulam nas diferentes formações sociais.

Para desenvolvermos uma melhor reflexão, é necessário compreender que, fundamentado no pensamento marxista, o mundo do trabalho é decorrente da relação ontológica homem - trabalho natureza, diz respeito a atividade humana fundamental de produção de sua natureza. Assim sendo os homens para existirem, para fazerem história, precisaram garantir a sobrevivência, de tal maneira que a primeira ação do homem foi criar meios para satisfazer tais necessidades, o objeto do trabalho é, portanto, a objetivação da vida genérica do homem.

O debate acerca da formação de professores não é algo recente. No entanto, revigoram-se essas discussões em decorrência não só de novos elementos, mas também devido a novas problemáticas significativas introduzidas, principalmente, em decorrência do Projeto de Mundialização do Capital (MELO, 2004) atualmente delineado pelas relações internacionais estabelecidas em acordos comerciais que exigem a formação de um novo tipo de trabalhador que corresponda às necessidades da mundialização do capital.

Como exemplo, podemos perceber um novo ordenamento do campo profissional da Educação Física que surge a partir do final dos anos 90, através da regulamentação da profissão, que opera, em última instância, uma reorientação no mundo do trabalho, do trabalho

Movimento, Porto Alegre, v. 14, n. 03, p. 209-232, setembro/dezembro de 2008. 
formal, assalariado nas escolas, para o trabalho não formal, de bens e serviços com a Lei 9696/98, que regulamenta a profissão de Educação Física no meio não formal, visto que no âmbito formal de ensino já era regulamentada pelo MEC. Nesse sentido, a reserva de mercado por meio da regulamentação da profissão é uma tese cabível no contexto neoliberal, visto que não trata da regulamentação que garanta direitos no campo do trabalho pelo qual o Estado deve se responsabilizar, colocando os trabalhadores em confronto, um com os outros. A lógica assumida é perfeitamente ajustada ao contexto individualista do capitalismo contemporâneo, dando por vencedora a tese da exclusão. Assim, vence a posição de que não se salvam todos neste modelo, e assim torna-se uma questão de corrida para a salvação individual (NOZAKI, 2004). O caso da regulamentação da profissão de Educação Física está apoiado em pressupostos corporativistas profissionais que atacam outros trabalhadores ao invés de centrar fogo nos detentores dos meios de produção, neste caso, os grandes proprietários do mundo das atividades físicas.

Para Günther e Molina Neto (2000), as mudanças curriculares surgidas a partir de final dos anos 70 e início dos anos 80 (corporificadas a partir da Resolução N. 03/87), ainda que apoiadas em um poderoso discurso, pouco trouxeram de alterações significativas ao que já estava posto. Persistindo a ausência de articulação mais significativa entre os conhecimentos específicos e os conteúdos relacionados à metodologia e práticas pedagógicas, resultou em um acúmulo de conhecimentos fragmentados que pouco contribui para uma prática pedagógica reflexiva e crítica dos futuros professores.

Outros estudos apontam a necessidade de uma transformação radical nos currículos dos cursos de Educação Física, cito o exemplo de duas dissertações de mestrado - Colavolpe (2005) e Domingues (2005), e uma tese de doutorado, Santos Jr. (2004), que apresentaram contradições encontradas no currículo, como a dicotomia entre teoria e prática, a descontextualização de conteúdos, a perda da historicidade do conhecimento, a diluição e superficialidade do conhecimento, problemas de formulação de generalizações e conceitos, a falta de estruturação lógica das disciplinas científicas e a falta de aplicabilidade em situações concretas do conhecimento tratado.

Movimento, Porto Alegre, v. 14, n. 03, p. 209-232, setembro/dezembro de 2008. 
O currículo é uma direção política do processo de formação humana, articulado, portanto, com um dado projeto histórico. Desta forma, a organização curricular anacrônica (isto é, desarticulada e incompatível com o atual momento histórico) nas faculdades de Educação Física compromete sobremaneira a percepção, a reflexão e as estratégias de ações que permitam uma avaliação e contraposição radical ao sistema capitalista, que, no atual momento de ajustes estruturais e conjunturais, constitui uma realidade marcada pela misera-bilidade da população mundial. ${ }^{5}$

No caso da Educação Física em particular, com a instituição das Diretrizes Curriculares Nacionais (DCN's) para o Curso de Bacharelado em Educação Física, dividindo a área de conhecimento em dois cursos separados - Licenciatura e Bacharelado - observase que a formação do professor está baseada nas competências que enfatizam a lógica do mercado e a uma simetria invertida: desenvolver habilidades que o mercado exige já na formação acadêmica. Taffarel (2007) argumenta que defender o bacharelado é fragmentar o conhecimento e desqualificar o trabalhador no processo de formação acadêmica, e que as DCNs consideram como objeto da Educação Física o "movimento humano", fechando a compreensão com base na perspectiva teórica desenvolvimentista e desconsidera a necessidade da definição de uma política global de formação humana.

O Parecer 776/97 do Conselho Nacional de Educação que tratou da orientação para DCN's dos Cursos de Graduação, quando faz alusão ao enfrentamento das transformações da sociedade, do mercado de trabalho e das condições de exercício profissional, diz respeito, na verdade, à reestruturação produtiva, crise e precarização do trabalho abstrato, ou seja, à busca de formação de um trabalhador de novo tipo para a gerência da crise do capital. Daí a necessidade de uma defesa de um currículo flexível, com variados tipos de formação e habilitações.

\footnotetext{
${ }^{5}$ Segundo a ONU, o número de pobres triplicou em 50 anos e chega a 1,3 bilhão de pessoas, pouco superior à população da China e equivalente a $22,8 \%$ do total mundial $(5,7$ bilhões de pessoas). Em 1947, o total de pobres correspondia a cerca de $17,4 \%$ da população mundial e, no mesmo período, as riquezas mundiais cresceram sete vezes, e o número de ricos dobrou, ampliando as desigualdades sociais. Os $20 \%$ mais pobres do mundo detêm só $1,1 \%$ das riquezas, e a subnutrição afeta 840 milhões de pessoas. 1,3 bilhões de pessoas sobrevivem com menos de US\$ 1 por dia, correspondendo a $22,8 \%$ da população mundial.
}

Movimento, Porto Alegre, v. 14, n. 03, p. 209-232, setembro/dezembro de 2008. 
Partindo de um pressuposto de neutralidade científica e inspirado em princípios de racionalidade, eficiência e produtividade, essa concepção de Educação Física advoga a reordenação do processo educativo de maneira a torná-lo objetivo e operacional (NOZAKI, 2004). De modo semelhante ao que ocorreu no trabalho fabril, pretende-se a objetivação do trabalho pedagógico. Com efeito, se no artesanato o trabalho era subjetivo, isto é, os instrumentos de trabalho eram dispostos em função do trabalhador e este dispunha deles segundo seus desígnios, na produção fabril essa relação é invertida. É o trabalhador que se adapta ao processo de trabalho, já que este foi objetivado e organizado na forma parcelada. Nessas condições, o trabalhador ocupa seu posto na linha de montagem e executa determinada parcela do trabalho, necessário para produzir determinados objetos. O produto é, pois, uma decorrência da forma como é organizado o processo. $\mathrm{O}$ concurso das ações de diferentes sujeitos produz assim um resultado com o qual nenhum dos sujeitos se identifica e que, ao contrário, lhes é estranho.

Todos esses elementos da formação inicial dos professores de Educação Física - contradição, fragmentação do currículo, desarticulação entre teoria e prática, expropriação do saber etc - são a base dos professores que, ao ingressarem no âmbito escolar, se deparam com uma realidade totalmente estranha àquela que foi apresentada durante sua formação inicial. Esse estranhamento ${ }^{6}$ é característico do processo histórico onde o capital, enquanto relação social, busca desvencilhar-se cada vez mais da dependência dos limites impostos pelo trabalhador, pela resistência que este lhes impõe, e desenha-se como um processo onde se busca expropriar do trabalhador os meios concretos desta resistência - seu saber, sua qualificação. A separação entre o operário e o seu instrumento vai determinando uma separação entre trabalhador e conhecimento, entre trabalhador e ciência.

A desqualificação do trabalhador, existente nesta perspectiva de formação do professor, cumpre mediações importantes para as

\footnotetext{
${ }^{6}$ Esse estranhamento é entendido, segundo Lukács (1960), como a existência de barreiras sociais que se opõem ao desenvolvimento da individualidade em direção à omnilateralidade humana, à individualidade emancipada. O capital contemporâneo, ao mesmo tempo em que pode, através do avanço tecnológico e informacional, potencializar as capacidades humanas, faz expandir o fenômeno social do estranhamento.
}

Movimento, Porto Alegre, v. 14, n. 03, p. 209-232, setembro/dezembro de 2008. 
necessidades do capital tanto no seu aspecto técnico-profissional quanto no seu aspecto político-cultural. A escola, onde se desenvolve o trabalho pedagógico, é um local agrega cada vez mais gente para um trabalho improdutivo forçado - e que, embora não produza mais-valia, é extremamente necessária ao sistema capitalista para a realização de mais-valia e, nesse sentido, ela é um trabalho produtivo.

Wittizorecki (2005), ao acompanhar a intervenção diária dos professores nas escolas da Rede Pública Municipal de Porto Alegre e ao ouvir seus relatos, afirma que o trabalho pedagógico compreende um processo complexo no qual suas ações transcendem o ato de ministrar aulas, havendo uma expectativa que abarque, também, outros campos que não só a educação escolar. Tal demanda ocorre em função do perfil da comunidade que o professorado atende, cujas necessidades não se limitam às questões educacionais, mas, fundamentalmente, englobam a premente urgência de condições sociais mais dignas e humanas de vida. Esse envolvimento e comprometimento retratam a forma como os professores concebem a docência e as próprias expectativas que têm em relação ao seu trabalho. Ao mesmo tempo em que apontam uma redefinição de seus papéis e atribuições, assumem estes, que por sua vez, pautam o trabalho docente que constroem. Os dilemas e inquietações com que os docentes se confrontam cotidianamente nas escolas, derivadas das características do cenário social em que estão inseridos, das contingências inerentes ao ato educativo e do caráter dinâmico e cambiante do trabalhar com outras pessoas, constituem a base necessária para que estes trabalhadores construam diariamente uma série de estratégias (como as operações de cooperação e aliança) e saberes (como a "capacidade de leitura" da realidade e a tolerância às adversidades), para lidarem com as demandas e necessidades que estas condições lhes colocam (WITTIZORECKI, 2005). Hernandez (2004) afirma que os professores têm uma "perspectiva funcional" (o que se aprende deve servir para algo) na sua formação profissional. Isto faz com que a maior parte dos saberes que os docentes trabalham nos cursos de formação, mesmo que não estejam bem legitimados academicamente, ao não serem produzidos nem legitimados pela prática docente, pouca relevância tenham em sua aprendizagem. No entanto, os professores não podem garantir a funcionalidade do que ensinam,

Movimento, Porto Alegre, v. 14, n. 03, p. 209-232, setembro/dezembro de 2008. 
não podem responder sobre para que vai servir a seus alunos, dadas as condições cambiáveis das circunstâncias de vida na sociedade contemporânea.

Ou seja, não é possível compreender a escola descontextualizada da realidade na qual está inserida, onde o ponto de partida deve ser a articulação do trabalho pedagógico com a prática social fundamental - a produção da existência. Por outro lado, uma prática social que se efetiva no interior da sociedade capitalista - cindida em classes é uma prática contraditória que engendra interesses antagônicos.

Historicamente, a organização da escola tem sido concebida tanto nas suas formas quanto no conteúdo, estritamente relacionada aos modelos organizacionais do trabalho produtivo e à regulamentação dos comportamentos e atitudes que sustentam a racionalização das sociedades modernas pelo Estado. Neste, a concepção de educação no modo de produção capitalista parte do pressuposto que as desigualdades sociais, os antagonismos de classes, os conflitos capitaltrabalho sejam superados por um processo meritocrático. Mascara-se o caráter orgânico da acumulação, concentração e centralização do capital e a própria luta de classes, na medida em que se nivela a capacidade de trabalho dos indivíduos "potenciada" com educação ou treinamento ao capital físico, ou seja, a força de trabalho se apresenta como uma mercadoria. O próprio estabelecimento de novas orientações ao processo educativo fica sob os auspícios do mercado. Como uma das conseqüências disso, temos a pedagogia das competências que orienta a formação do indivíduo pautada pelo mercado, sendo a escola uma instituição mediadora do processo produtivo.

Num dos estudos etnográficos do F3P-EFICE desenvolvido por Santini e Molina Neto (2005), constatou-se que num contexto maior onde os professores vêm sendo levados ao papel de técnicos executores, tentar que construam uma prática transformadora é "andar na contramão" e, mesmo no contexto de mudanças que vêm acontecendo no interior da rede, ${ }^{7}$ há que se considerar que a questão da autonomia das escolas e do professorado é ainda uma questão mal equacionada e que exigirá a superação de muitas contradições

${ }^{7}$ Referindo-se a Rede Pública Municipal de Porto Alegre.

Movimento, Porto Alegre, v. 14, n. 03, p. 209-232, setembro/dezembro de 2008. 
para que venha a avançar. Do ponto de vista de como o professor convive e percebe a relação professor/aluno em seu cotidiano, faz com que, muitas vezes, tenha que alterar a postura de condução de suas aulas a fim de poder exercer o controle disciplinar sobre os alunos. O professor constrói um modo de abandonar o trabalho, apesar de continuar no posto de trabalho. O exemplo claro a esse respeito é o do "professor-bola", ou seja, aquele professor que reduz sua prática pedagógica a deixar uma bola para os alunos praticarem alguma modalidade esportiva.

Desse modo, o mal-estar docente referido traz inúmeras conseqüências do trabalho na vida do professor. Uma delas diz respeito ao confronto entre a realidade idealizada pelo professor e a encontrada no âmbito escolar. Durante o processo de formação inicial, a maior parte dos professores adquire e desenvolve um modelo ajustado a pressupostos idealistas não contrastados com a realidade cotidiana dos centros escolares. Assim, o enfrentamento desse cotidiano escolar leva os professores a refletirem sobre o valor de seu próprio trabalho. Eles revelam um quadro de medo, ansiedade e insegurança no ambiente de trabalho que, ao fazer parte do seu cotidiano, conduz os professores, em estados mais graves, à depressão, comprometendo sua função educativa (SANTINI; MOLINA NETO, 2005). Neste mesmo estudo observou-se que em grande parte dos professores entrevistados foi possível identificar quadros de exaustão emocional, despersonalização e falta de realização pessoal no trabalho, características associadas diretamente a Síndrome do Esgotamento Profissional.

As mudanças ocorridas nas relações de trabalho e emprego têm sido caracterizadas, na atualidade, pela ameaça de um fenômeno considerado por alguns autores como uma precarização das relações de trabalho. Tal movimento, contudo, não se circunscreve às relações de trabalho caracterizadas como aquelas intrínsecas ao processo de trabalho, mas compreende principalmente as relações de emprego, apresentando uma tentativa de flexibilização e, até mesmo, desregulamentação da legislação trabalhista. A flexibilidade aparece na organização do trabalho nas empresas como necessária às novas formas de produção comandadas pelo mercado. Ao contrário do modelo fordista de produção em série, voltado para o consumo de massa,

Movimento, Porto Alegre, v. 14, n. 03, p. 209-232, setembro/dezembro de 2008. 
demandando grandes estoques, o momento atual sugere formas mais flexíveis de organização e gestão do trabalho. A rígida divisão das tarefas, característica marcante do fordismo, vem cedendo lugar a formas mais horizontais e autônomas de organização do trabalho, permitindo maior adaptabilidade dos trabalhadores às situações novas, possibilitando a intensificação da exploração do trabalho. Temos observado em nossas pesquisas que os professores se sentem obrigados a responder às novas exigências pedagógicas e administrativas, contudo expressam sensação de insegurança e desamparo tanto do ponto de vista objetivo - faltam-lhes condições de trabalho adequadas - quanto do ponto de vista subjetivo.

Nesse sentido, a finalidade do trabalho pedagógico, articulado ao processo de trabalho capitalista, é o disciplinamento para a vida social e produtiva, em conformidade com as especificidades que os processos de produção, em decorrência do desenvolvimento das forças produtivas, vão assumindo (KUENZER, 2002). O trabalho pedagógico fica subordinado à esfera de produção, onde o professor se insere na linha de montagem e sua função primeira é preparar os filhos dos trabalhadores para o mercado de trabalho. O tempo de aprender não tem valor por si mesmo; é simplesmente uma preparação para a "verdadeira vida", ou seja, o trabalho produtivo, ao passo que, comparativamente, a escolarização é dispendiosa, improdutiva ou, quando muito, reprodutiva (TARDIF; LESSARD, 2005, p. 17).

No âmbito dessa pedagogia toyotista, as capacidades mudam e são chamadas de competências, ao invés de habilidades psicofísicas, fala-se em desenvolvimento de competências cognitivas complexas, mas sempre com o objetivo de atender às exigências do processo de valorização do capital. Com relação a este modelo pedagógico das competências, percebemos a existência de uma dicotomia onde, ao mesmo tempo em que a educação é tida como fator de mobilidade social e de desenvolvimento econômico individual - escola produtiva -, as condições precarizadas da realidade escolar não permitem que os indivíduos tenham acesso ao conhecimento necessário que possibilite algum tipo de ascensão social ou desenvolvimento econômico - escola improdutiva. Esta dicotomia, na concepção de Frigotto (1999), torna-se funcional ao capital na medida em que a escola improdutiva serve de mediação para gerir a crise do capital, tornando-

Movimento, Porto Alegre, v. 14, n. 03, p. 209-232, setembro/dezembro de 2008. 
se assim, produtiva. Trabalho produtivo e improdutivo, embora de naturezas distintas, são partes de um mesmo movimento total: da produção, circulação e realização do valor.

Duas vertentes críticas alimentam a controvérsia das relações entre a prática educacional escolar e a estrutura econômico-social no interior do capitalismo atual (FRIGOTTO, 1999):

a) a dos que vêem a educação como potenciadora de trabalho e, portanto, geradora de produtividade, o que representa não um aumento de renda para o trabalhador, mas um mecanismo de aumento de exploração e de extração de mais-valia relativa, pelo capital;

b) a posição segundo a qual tanto os teóricos do capital humano quanto seus "críticos" estão equivocados, na medida em que a escola está situada à margem do sistema produtivo capitalista, cujo único vínculo é o ideológico.

A inserção da educação (escolar e não escolar) no movimento global do capital, a nosso ver, existe e se dá por um processo de diferentes mediações. $\mathrm{O}$ vínculo não é direto pela própria natureza e especificidade da prática educativa, e não se constitui numa prática social fundamental, mas numa prática mediadora desse movimento.

\section{CONSIDERAÇÕES FINAIS}

Partindo da produção teórica do grupo F3P-EFICE, buscamos avançar no debate acerca da formação de professores e do trabalho pedagógico em Educação Física, para compreender a forma como o trabalho pedagógico se materializa na prática social das atuais condições da educação brasileira, inserida no seio do modo de produção capitalista. Certos de que o debate não se encerra por aqui, apontamos alguns elementos que permitirão ampliar estas discussões.

Estas constatações levantadas em exaustivos trabalhos de campo, observações, entrevistas, diários etc., nos fazem compreender que a realidade da Educação Física escolar é marcada pela má qualificação da formação de professores, descontextualização e precarização do trabalho pedagógico. Constatações estas que caracterizam as

Movimento, Porto Alegre, v. 14, n. 03, p. 209-232, setembro/dezembro de 2008. 
transformações atuais do movimento das forças produtivas no modo de produção capitalista. Marcadas pela passagem do modelo taylorista/fordista para uma reestruturação produtiva da era da acumulação flexível, onde os métodos flexíveis de organização e gestão de trabalho não só exigem novas competências, como também invadem a escola com estes novos princípios.

Como vimos, a improdutividade da Educação Física escolar que se consolida na formação de professores e na articulação com o trabalho pedagógico, no modo de produção capitalista de organizar a vida, torna-se produtiva para gerir as crises do capital e tornar a escola um instrumento mediador desta crise. É necessário para o capital transformar a classe-que-vive-do-traballho em mão-de-obra disponível, desqualificada, precarizada e alienada, ou seja, produzir um exército de reserva funcional. Trata-se de preparar os indivíduos para a condição de desempregados, deficientes, mãe-solteira etc.

Convictos de que a educação, por si só, não é capaz de transformar o modo de produzir e reproduzir a vida na atual conjuntura entendemos que o trabalho pedagógico pode servir de processo para a emancipação/humanização, através de uma pedagogia revolucionária.

Este movimento contraditório humanização/alienação interessa muito à educação. Parece que esta questão é fundamental para a organização do processo educacional. A educação estará, em suas várias dimensões, "a serviço" da humanização ou da alienação? Esta pergunta tem que ser respondida pelo educador, como direção de sua prática pedagógica, pois não há possibilidade de construção de um agir pedagógico sem que esta questão esteja presente. O conhecimento, como instrumento particular do processo educacional, pode ser tratado de forma a contribuir ou a negar o processo de humanização. Para que a educação seja um instrumento do processo de humanização, o trabalho deve aparecer como princípio educativo. Isto quer dizer que a educação não pode estar voltada para o trabalho de forma a responder às necessidades adaptativas, funcionais, de treinamento e domesticação do trabalhador, exigidas em diferentes graus, pelo mundo do trabalho na sociedade moderna, mas sim que a educação pode ter como preocupação fundamental o trabalho em sua forma mais ampla.

Movimento, Porto Alegre, v. 14, n. 03, p. 209-232, setembro/dezembro de 2008. 


\begin{abstract}
The Productivity of Physical Education Improductive

Abstract: This article if originated in the researchs developed in the Group of Qualitatives Studies Teachers Formation and Pedagogical Practical in Physical Education and Sports Science (F3P-EFICE) of UFRGS. For this text, problematized the formation and the pedagogical practical of physical education teachers, leaving from the knowledge produced of this group. We will search to identify, therefore, the contributions that these productions had brought for the academic field concerning the thematic of the teachers formation and pedagogical practical in physical education; and of that it forms this if articulates with the inserted brazilian educational reality in the capitalist production mode.

Keywords: School Physical Education. Teachers
\end{abstract} Formation. Padagogical Practical.

\footnotetext{
La Productividad de la Educación Fisica Improductiva

Resumen: Este artículo tiene su origen en las investigaciones desarrolladas en el marco del Grupo de Estudios Cualitativos Formación de Profesores y Práctica Pedagógica en Educación Física y Ciencias del Deporte (F3P-EFICE). Hicimos un análisis crítico de la formación y de la practica pedagógica en Educación Física, empezando del conocimiento ya producido por este grupo. Además, intentamos identificar las contribuciones que ellas han aportado para el campo académico sobre ese tema y como se articulan con la realidad educativa inserida en el modo de producción capitalista

Palabras-clave: Educación Fisica Escolar. Formación de Profesores. Practica Pedagogica.
}

\title{
REFERÊNCIAS
}

ANTUNES. R. O trabalho, a produção destrutiva e a des-realização da Liberdade. In: CARRION, R.; VIZENTINI, P. A Crise do Capitalismo na Virada do Milênio. Porto Alegre: Ed. UFRGS, Cedesp. 2000. p. 112-120.

BEZERRA, C.; PAZ, S. R. Profissionalização e Formação Docente: Dimensões e Diferenciações Epistemológicas entre Prática Pedagógica e Trabalho Pedagógico. In: ENCONTRO INTERNACIONAL TRABALHO E PERSPECTIVAS DE FORMAÇÃO

Movimento, Porto Alegre, v. 14, n. 03, p. 209-232, setembro/dezembro de 2008. 
DOS TRABALHADORES, 1. 2006. Fortaleza: Anais... Fortaleza: LABOR/UFC, 2006. p. $2-14$

COLAVOLPE; Carlos Roberto. O Esporte como conteúdo nos cursos de formação de professores: realidade e possibilidades, 2005, 235 fls. Dissertação (Mestrado) 2005 - Universidade Federal da Bahia. Faculdade de Educação, Salvador, 2005

DOMINGUES, Soraya Correa. Cultura Corporal e meio-ambiente na formação de professores. 289 fls. Dissertação (Mestrado). Universidade Federal da Bahia - Faculdade de Educação, 2005.

ENGUITA, Mariano F. A face oculta da escola. Porto Alegre: Artes Médicas, 1993.

FREITAS, Luiz Carlos de. Crítica da Organização do trabalho pedagógico e da Didática. Campinas: Papirus, 1995.

A Organização do Trabalho Pedagógico: Elementos para a Pesquisa de Novas Formas de Organização. In: ENCONTRO NACIONAL DE DIDÁTICA E PRÁTICA DE ENSINO, 5. 1989. Anais... Belo Horizonte, 1989.

FRIGOTTO, G. A produtividade da escola improdutiva. São Paulo: Cortez, 1999.

GAMBOA, S. A. S. A dialética na pesquisa em educação: elementos de contexto. In: FAZENDA, I. (Org.) Metodologia da pesquisa educacional. São Paulo: Cortez, 1989.

GÜNTHER, Maria C.; MOLINA NETO, V. Formação Permanente de Professores de Educação Física na Rede Municipal de Ensino de Porto Alegre: uma Abordagem Etnográfica. Rev. Paulista de Educação Física, São Paulo, v. 14, n. 1, p. 85-91, jan/jun 2000.

HERNANDÉZ, F.; A Formação do Professorado e a Investigação Sobre a Aprendizagem dos Docentes. In: MOLINA NETO, V.; TRIVIÑOS, A. A Pesquisa Qualitativa na Educação Física. 2. ed. Porto Alegre, Ed. UFRGS, 2004.

KOPNIN, P. V. A Dialética como Lógica e Teoria do Conhecimento. Rio de Janeiro: Ed. Civilização Brasileira, 1978.

KUENZER, A. Z. Exclusão Includente e Inclusão Excludente. In: LOMBARDI, J.; SAVIANI, D.; SANFELICE, J. Capitalismo, Trabalho e Educação. Campinas: Autores Associados, 2002.

Pedagogia da fábrica: as relações de produção e a educação do trabalhador. São Paulo: Cortez, Autores Associados, 1986.

LUKÁCS, G. História e Consciência de Classe. São Paulo: Ed. PCUS. 1960

MARX, K. O Capital. Rio de Janeiro; Civilização Brasileira, 1980. v. 1.

Movimento, Porto Alegre, v. 14, n. 03, p. 209-232, setembro/dezembro de 2008. 
MELO, A. S.; A mundialização da educação. Consolidação do projeto neoliberal na América Latina: Brasil e Venezuela. 1. ed. Maceió: Editora da Universidade Federal de Alagoas, 2004.

MOLINA NETO, V. A formação profissional em educação física e esportes. Revista Brasileira de Ciências do Esporte, Movimento, Porto Alegre, v. 19, n.1, p. 31- 44, 1997.

MOLINA NETO, V. Etnografia: Uma Opção Metodológica para Alguns Problemas de Investigação no Âmbito da Educação Física. In: MOLINA NETO, V.; TRIVIÑOS, A.; A Pesquisa Qualitativa na Educação Física. 2. ed. Porto Alegre, Ed. UFRGS, 2004.

NOZAKI, Hajime Takeuchi. Educação Física e reordenamento no mundo do trabalho: mediações da regulamentação da profissão. 2004. Tese (Doutorado) - Faculdade de Educação, Universidade Federal Fluminense, Niterói, 2004.

SADER, E. Prefácio In: MESZÁROS, Istvan. Educação Para Além do Capital. Boitempo, São Paulo, 2005.

SANTINI, Joarez; MOLINA NETO, Vicente. A síndrome do esgotamento profissional em professores de educação física: um estudo da rede municipal de ensino de Porto Alegre; Revista Brasileira Educação Física Esportiva, São Paulo, v. 19, n.3, p. 209-22, jul/set 2005.

SANTOS Jr., Cláudio de Lira. A formação de professores em educação fisica: a mediação dos parâmetros teórico-metodológicos. Tese - Doutorado. UFBA. 2005

TAFFAREL, Celi N. Z. Formação de Professores: Estratégia e Tática; Disponível em: <http://www.faced.ufba.br/rascunho_digital/>. Acesso em: 17 de março de 2007.

TARDIF, M.; LESSARD, C. O Trabalho Docente - Elementos para uma teoria da docência como profissão das interações humanas. Petrópolis, 2005

Recebido em: 20/11/2007

Aprovado em: 17/03/2008

Movimento, Porto Alegre, v. 14, n. 03, p. 209-232, setembro/dezembro de 2008. 